\title{
Decline in influenza vaccine effectiveness with time after vaccination, Navarre, Spain, season 2011/12
}

J Castilla (jcastilc@navarra.es) 1,2, I Martínez-Baz ${ }^{1,2}$, V Martínez-Artola ${ }^{3}$, G Reina 4 , F Pozo5, M García Cenoz ${ }^{1,2}$, M Guevara $^{1,2}$, J Morán ${ }^{6}$, F Irisarri'1,2, M Arriazu ${ }^{1,2}$, E Albéniz ${ }^{6}$, C Ezpeleta ${ }^{3}$, A Barricarte ${ }^{1,2}$, Primary Health Care Sentinel Network ${ }^{7}$, Network for Influenza Surveillance in Hospitals of Navarre ${ }^{7}$

1. Instituto de Salud Pública de Navarra (Public Health Institute of Navarre), Pamplona, Spain

2. Centro de Investigación Biomédica en Red de Epidemiología y Salud Pública (CIBERESP; Network of Biomedical Research Centers Epidemiology and Public Health), Spain

3. Complejo Hospitalario de Navarra (Hospital complex of Navarre), Pamplona, Spain

4. Clínica Universidad de Navarra (University Clinic of Navarre), Pamplona, Spain

5. National Centre of Microbiology (World Health Organization National Influenza Centre - Madrid), Instituto de Salud Carlos III, Majadahonda, Spain

6. Primary Healthcare Directorate, Navarre Health Service, Pamplona, Spain

7. The members of these networks are listed at the end of the article

Citation style for this article:

Castilla J, Martínez-Baz I, Martínez-Artola V, Reina G, Pozo F, García Cenoz M, Guevara M, Morán J, Irisarri F, Arriazu M, Albéniz E, Ezpeleta C, Barricarte A, Primary Health Care Sentinel Network, Network for Influenza Surveillance in Hospitals of Navarre. Decline in influenza vaccine effectiveness with time after vaccination, Navarre, Spain, season 2011/12. Euro Surveill. 2013;18(5):pii=20388. Available online: http://www.eurosurveillance.org/ViewArticle.aspx?Articleld=20388

This study evaluates the influenza vaccine effectiveness (VE) in preventing laboratory-confirmed cases in Navarre, Spain, in the 2011/12 season in which the peak was delayed until week 7 of 2012. We conducted a test-negative case-control study. Patients with influenza-like illness in hospitals and primary healthcare were swabbed for testing by reverse transcription-polymerase chain reaction. Influenza vaccination status and other covariates were obtained from healthcare databases. The vaccination status of confirmed cases and negative controls was compared after adjusting for potential confounders. VE was calculated as (1-odds ratio)x100. The 411 confirmed cases (93\% influenza $\mathrm{A}\left(\mathrm{H}_{3}\right)$ ) were compared with 346 controls. Most characterised viruses did not match the vaccine strains. The adjusted estimate of VE was $31 \%$ ( $95 \%$ confidence interval (Cl): -21 to 60 ) for all patients, $44 \%$ (95\% Cl: -11 to 72$)$ for those younger than 65 years and $19 \%(95 \% \mathrm{Cl}:-146$ to 73$)$ for those 65 or older. The VE was $61 \%$ ( $95 \% \mathrm{Cl}: 5$ to 84 ) in the first 100 days after vaccination, $42 \%(95 \% \mathrm{Cl}$ : -39 to 75) between 100 and 119 days, and zero thereafter. This decline mainly affected people aged 65 or over. These results suggest a low preventive effect of the 2011/12 seasonal influenza vaccine, and a decline in VE with time since vaccination.

\section{Introduction}

Influenza is an important health problem that can lead to serious complications in persons with risk factors $[1,2]$. Annual vaccination is the primary measure for preventing influenza and its complications [3]. Because the influenza vaccine composition is adapted each season to the viruses in circulation, its effectiveness varies [4].

Observational studies are the main way to evaluate vaccine effectiveness (VE) in each season, however, possible biases affecting comparability between vaccinated and unvaccinated persons must be overcome [5-8]. Studies with non-specific outcomes tend to underestimate the VE [6], a problem that is resolved by analysing virologically confirmed cases $[4,9]$. A design that compares confirmed influenza cases with testnegative controls ensures good comparability and is easy to carry out, thus this type of study has come to be widely used $[4,9]$.

Song et al., in an immunogenicity study of the influenza vaccine, found that the antibody levels decline progressively, beginning in the first months after vaccine administration [10]. In addition, people with higher risk of complications due to influenza may have a weaker immune response due to the immunodepression associated with some chronic diseases or to the immunosenescence associated with aging $[11,12]$.

In Spain, influenza circulation in the 2011/12 season reached a peak in week 7 of 2012, the second latest peak in the past 15 seasons, after the 2005/06 influ-

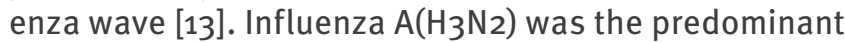
virus in circulation, and a certain degree of vaccinevirus mismatch was observed [13]. The objective of this study was to describe the effectiveness of the influenza vaccine in the 2011/12 season in preventing laboratory-confirmed influenza, including both outpatients and hospitalised patients.

\section{Methods}

Study population

The present study was based on electronic clinical records in the region of Navarre, Spain in the 2011/12 season. The Navarre Ethical Committee for Medical Research approved the study protocol. The Navarre Health Service provides healthcare, free at point of 
service, to $97 \%$ of the 642,051 inhabitants of the region (private companies provide healthcare to the remaining $3 \%$ of the population). The clinical records have been computerised since the year 2000 and include reports from primary care, hospital admissions, vaccination register, and laboratory test results.

The seasonal vaccination campaign took place from 10 October to 25 November 2011. In Navarre the trivalent inactivated non-adjuvanted vaccine was recommended and offered free of charge to people aged 60 years or older and to those with risk factors or major chronic conditions [14]. Other people can also be vaccinated if they pay for the vaccine. In the 2011/12 season, the vaccine included the strains $\mathrm{A} / \mathrm{California/07/2009}\left(\mathrm{H}_{1} \mathrm{~N}_{1}\right)$-like, A/Perth/16/2009(H3N2)-like and B/Brisbane/60/2008like virus [15]. Precise instructions for registering each dose were given to all vaccination points [14].

Influenza surveillance was based on automatic reporting of cases of influenza-like illness (ILI) from all primary healthcare centres and hospitals. Following the European Union case definition, ILI was considered to be the sudden onset of any general symptom (fever or feverishness, malaise, headache or myalgia) in addition to any respiratory symptom (cough, sore throat or shortness of breath) [16]. A sentinel network composed of a representative sample of 76 primary healthcare physicians and paediatricians, covering $15 \%$ of the population, was asked to take nasopharyngeal and pharyngeal swabs, after obtaining verbal informed consent, from all their patients diagnosed with ILI whose symptoms had begun preferably less than five days previously. An agreed protocol of care for influenza cases was applied in hospitals, which specified early detection and nasopharyngeal swabbing of all hospitalised patients with ILI. Swabs were analysed by reverse transcription polymerase chain reaction (RT-PCR), and influenza-positive samples were subsequently typed/ subtyped as influenza $A\left(\mathrm{H}_{1}\right.$ and $\left.\mathrm{H}_{3}\right), A\left(\mathrm{H}_{1} \mathrm{~N}_{1}\right)$ pdmo9 and $\mathrm{B}$. About one in four positive swabs was randomly selected each week and sent to the National Influenza Centre-Madrid laboratory for genetic characterisation.

\section{Study design and statistical analysis}

We carried out a case-control study nested in the cohort of the population covered by the Navarre Health Service. Healthcare workers, persons living in nursing homes and children under six months of age were excluded. The study began in the first week in which influenza virus was detected, 12 December 2011 (week 50 ), and ended in the last week in which ILI patients tested positive for influenza, 20 May 2012 (week 20).

The cases were patients diagnosed with ILI in primary care or in hospitals who were confirmed for influenza virus by RT-PCR. The controls were patients with ILI in primary healthcare or in hospitals who were negative for influenza virus. Their vaccination status for the trivalent 2011/12 seasonal influenza vaccine was obtained from the online regional vaccination register [17]. Subjects were considered to be protected starting 14 days after vaccine administration.

\section{FIGURE}

Number of influenza cases and test-negative controls, and incidence of influenza-like illness by week, Navarre,

3 Oct 2011-20 May 2012

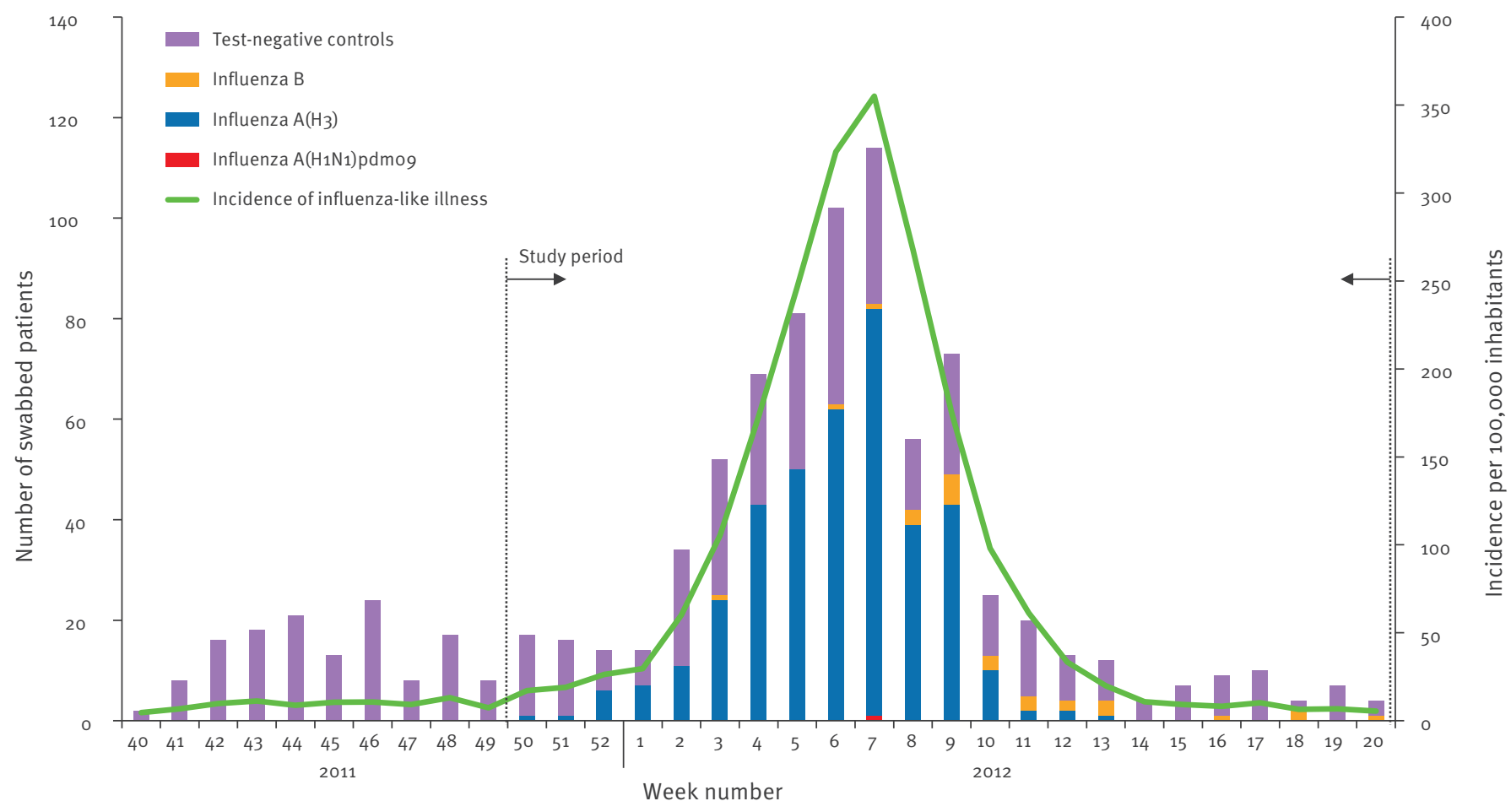


From the electronic healthcare records we obtained the following baseline characteristics: sex, age, district of residence, migrant status (country of birth other than Spain has been related to a different pattern of use of healthcare services [18]), major chronic conditions (heart disease, lung disease, renal disease, cancer, diabetes mellitus, cirrhosis, dementia, stroke, immunodeficiency, rheumatic disease and body mass index of $40 \mathrm{~kg} / \mathrm{m} 2$ or greater), hospitalisation in the previous 12 months and outpatient visits in the previous 12 months.

Vaccination status was compared between cases and controls. Different analyses were done: (i) comparing cases of each type of influenza with negative controls, (ii) including only patients in whom influenza vaccination was indicated because they were 60 years or older or had a major chronic condition, (iii) considering only patients in primary care, and (iv) including only swabs taken in the first four days after symptom onset. VE was also evaluated separately in two age strata ( 165 and $\geq 65$ years; a cut-off age different from that of the vaccination target population was chosen to match the one commonly used in similar studies), in two periods (weeks 50/2011 to week 8/2012 and weeks 9/2012 to 20/2012) and in three strata according to time since vaccination ( $(100,100-119$ and $\geq 120$ days).

Percentages were compared by chi-square test. Logistic regression techniques were used to calculate the odds ratios (OR) with their $95 \%$ confidence intervals $(\mathrm{Cl})$. ORs were adjusted for potential confounders including healthcare setting, and for date of diagnosis grouped into four-week periods. VE was estimated as (1-OR)x100.

\section{Results}

\section{Description of cases and controls}

The weekly number of swabbed patients followed the pattern of ILI incidence in the population (Figure). During the study period, 757 ILI patients were swabbed, 588 in primary healthcare and 169 in hospitals. Some 411 (54.3\%) were confirmed for influenza virus: 382 for influenza $A\left(\mathrm{H}_{3}\right), 28$ for influenza $B$ and one for influenza $A\left(\mathrm{H}_{1} \mathrm{~N}_{1}\right)$ pdmog.

Compared with confirmed cases of influenza, the group of test-negative controls had a higher proportion of males, of persons under the age of five years, people who had consulted a physician five or more times in the past year, who had major chronic conditions, and who were treated in hospital. There were no significant differences regarding migrant status or urban/ rural residence, and these variables were therefore not included in the multivariate analysis (Table 1). Vaccine coverage in controls (18.8\%) was slightly higher than in the overall population cohort in which the study was nested $(14.2 \%, p=0.015)$.
Effectiveness of the 2011/12 seasonal influenza vaccine

Compared with test-negative controls, a smaller proportion of confirmed influenza cases had received the 2011/12 seasonal influenza vaccine (OR: 0.60; $95 \% \mathrm{Cl}$ : 0.40 to $0.89 ; p=0.012)$. In the adjusted analysis, the VE was $31 \%$ (95\% Cl: -21 to $60 ; p=0.200)$. The VE was somewhat higher between weeks 50/2011 and 8/2012

\section{TABLE 1}

Characteristics of laboratory-confirmed influenza cases $(\mathrm{n}=411)$ and test-negative controls $(\mathrm{n}=346)$, Navarre, 12 Dec 2011-20 May 2012

\begin{tabular}{|c|c|c|c|}
\hline & $\begin{array}{l}\text { Laboratory- } \\
\text { confirmed } \\
\text { influenza } \\
\text { cases } \\
\text { n (\%) }\end{array}$ & $\begin{array}{l}\text { Test- } \\
\text { negative } \\
\text { controls } \\
\text { n (\%) }\end{array}$ & $p$ value \\
\hline \multicolumn{3}{|l|}{ Age groups (years) } & $<0.001$ \\
\hline$<5$ & $28(6.8)$ & $56(16.2)$ & - \\
\hline $5-14$ & $50(12.2)$ & $40(11.6)$ & - \\
\hline $15-44$ & $164(39.9)$ & $123(35 \cdot 5)$ & - \\
\hline $45-64$ & $115(28.0)$ & $74(21.4)$ & - \\
\hline$\geq 65$ & $54(13.1)$ & $53(15.3)$ & - \\
\hline \multicolumn{3}{|l|}{ Sex } & 0.006 \\
\hline Male & $188(45.7)$ & $194(56.1)$ & - \\
\hline Female & $223(54 \cdot 3)$ & $152(43.9)$ & - \\
\hline \multicolumn{3}{|l|}{ Residence } & 0.164 \\
\hline Rural & $103(25.1)$ & $103(29.8)$ & \\
\hline Urban & $308(74.9)$ & $243(70.2)$ & \\
\hline \multicolumn{3}{|l|}{ Migrant status } & 0.097 \\
\hline No & $381(92.7)$ & $308(89.0)$ & - \\
\hline Yes & $30(7.3)$ & $38(11.0)$ & - \\
\hline \multicolumn{3}{|l|}{ Major chronic conditions } & 0.002 \\
\hline No & $301(73.2)$ & $217(62.7)$ & - \\
\hline Yes & $110(26.8)$ & $129(37.3)$ & - \\
\hline \multicolumn{3}{|c|}{ Hospitalisation in the previous year } & $<0.001$ \\
\hline No & $384(93.4)$ & $292(84.4)$ & - \\
\hline Yes & $27(6.6)$ & $54(15.6)$ & - \\
\hline \multicolumn{3}{|c|}{ Outpatient visits in the previous year } & 0.016 \\
\hline 0 & $44(11.4)$ & $32(9.3)$ & - \\
\hline 1 to 5 & $195(47.5)$ & $133(38.4)$ & - \\
\hline$>5$ & $172(41.9)$ & $181(52.3)$ & - \\
\hline \multicolumn{3}{|l|}{ Health care setting } & $<0.001$ \\
\hline Primary healthcare & $378(92.0)$ & $210(60.7)$ & - \\
\hline Hospital & $30(7.3)$ & $119(34.9)$ & - \\
\hline Emergency rooms & $3(0.7)$ & $17(4 \cdot 9)$ & - \\
\hline \multicolumn{3}{|l|}{ Period } & $<0.001$ \\
\hline $\begin{array}{l}\text { Weeks 50/2011 to 8/2012 } \\
\text { (12 Dec 2011-26 Feb 2012) }\end{array}$ & $332(80.8)$ & $237(68.5)$ & - \\
\hline $\begin{array}{l}\text { Weeks 9/2012 to } 20 / 2012 \\
\text { (27 Feb-20 May 2012) }\end{array}$ & $79(19.2)$ & $109(31.5)$ & - \\
\hline \multicolumn{3}{|c|}{ Seasonal influenza vaccine $2011 / 12$} & $<0.015$ \\
\hline No & $361(87.8)$ & $281(81.2)$ & - \\
\hline Yes & $50(12.2)$ & $65(18.8)$ & - \\
\hline Total & $411(100)$ & $346(100)$ & - \\
\hline
\end{tabular}


(37\%; 95\% Cl: -18 to 67$)$, and lower between weeks 9/2012 and 20/2012 (19\%; 95\% Cl: -176 to 76). The estimates of VE were very similar in the analyses that were restricted to cases of influenza $\mathrm{A}\left(\mathrm{H}_{3}\right)(29 \% ; 95 \% \mathrm{Cl}$ : -26 to 60 ), to subjects with an indication for vaccination (30\%; $95 \% \mathrm{Cl}:-34$ to 63$)$, to patients in primary care (31\%; $95 \% \mathrm{Cl}:-32$ to 64$)$, and to patients swabbed within the first four days after symptom onset $(29 \%$; $95 \% \mathrm{Cl}:-38$ to 63$)$. The point estimate of the VE was higher in subjects under the age of 65 years (44\%; $95 \%$ $\mathrm{Cl}:-11$ to 72$)$ than in those aged 65 years or older $(19 \%$; $95 \% \mathrm{Cl}:-146$ to 73 ), although these differences did not reach statistical significance. In none of all the analyses was the VE statistically significant (Table 2).

The VE was $61 \%$ ( $95 \% \mathrm{Cl}: 5$ to 84 ) in the first 100 days after vaccination, dropping to $42 \%(95 \% \mathrm{Cl}:-39$ to 75 ) between days 100 and 119 , and ceasing to confer any protection after 120 days $(-35 \%, 95 \% \mathrm{Cl}:-211$ to 41) (Table 3). Persons vaccinated more than 120 days before diagnosis versus those vaccinated less than 100 days before diagnosis were at an increased risk for contracting influenza, with an OR of 3.45 (95\% Cl: 1.10 to $10.85 ; p=0.034)$.

\section{TABLE 2}

Influenza vaccine effectiveness in preventing laboratory-confirmed influenza by patient characteristic, comparisons of influenza-positive cases $(n=411)$ and test-negative controls $(n=346)$, Navarre, 12 Dec 2011-20 May 2012

\begin{tabular}{|c|c|c|c|c|c|}
\hline & Cases/controls & $\begin{array}{l}\text { Crude vaccine } \\
\text { effectiveness } \\
\%(95 \% \mathrm{Cl})\end{array}$ & $\mathrm{p}$ value & $\begin{array}{c}\text { Adjusted vaccine } \\
\text { effectiveness } \\
\%(95 \% \mathrm{Cl})^{\mathrm{a}}\end{array}$ & $\mathrm{p}$ value \\
\hline \multicolumn{6}{|c|}{ All swabbed patients } \\
\hline Unvaccinated & $361 / 281$ & Reference & - & Reference & - \\
\hline Vaccinated & $50 / 65$ & $40(11$ to 60$)$ & 0.012 & $31(-21$ to 60$)$ & 0.200 \\
\hline \multicolumn{6}{|c|}{ Weeks 50/2011 to 8/2012 (12 Dec 2011-26 Feb 2012) } \\
\hline Unvaccinated & $298 / 195$ & Reference & - & Reference & - \\
\hline Vaccinated & $34 / 42$ & $47(14$ to 67$)$ & 0.011 & $37(-18$ to 67$)$ & 0.151 \\
\hline \multicolumn{6}{|c|}{ Weeks 9/2012 to 20/2012 (27 Feb 2012-20 May 2012) } \\
\hline Unvaccinated & $63 / 86$ & Reference & - & Reference & - \\
\hline Vaccinated & $16 / 23$ & $15(-94$ to 54$)$ & 0.888 & $19(-176$ to 76$)$ & 0.741 \\
\hline \multicolumn{6}{|l|}{ Influenza $\mathrm{A}\left(\mathrm{H}_{3}\right)^{\mathrm{b}}$} \\
\hline Unvaccinated & $335 / 281$ & Reference & - & Reference & - \\
\hline Vaccinated & $47 / 65$ & 39 (9 to 60$)$ & 0.011 & $29(-26$ to 60$)$ & 0.247 \\
\hline \multicolumn{6}{|l|}{ Influenza B ${ }^{\mathrm{b}}$} \\
\hline Unvaccinated & $25 / 281$ & Reference & - & Reference & - \\
\hline Vaccinated & $3 / 65$ & $48(-77$ to 85$)$ & 0.295 & $54(-102$ to 90$)$ & 0.301 \\
\hline \multicolumn{6}{|c|}{ Target population for vaccination ${ }^{c}$} \\
\hline Unvaccinated & $112 / 98$ & Reference & - & Reference & - \\
\hline Vaccinated & $43 / 54$ & $30(-13$ to 57$)$ & 0.143 & $30(-34$ to 63$)$ & 0.286 \\
\hline \multicolumn{6}{|c|}{ Primary healthcare patients } \\
\hline Unvaccinated & $337 / 185$ & Reference & - & Reference & - \\
\hline Vaccinated & $41 / 25$ & $10(-53$ to 47$)$ & 0.697 & $31(-32$ to 64$)$ & 0.262 \\
\hline \multicolumn{6}{|c|}{ Hospitalised patients } \\
\hline Unvaccinated & $21 / 85$ & Reference & - & Reference & - \\
\hline Vaccinated & $9 / 34$ & $-7(-157$ to 65$)$ & 0.877 & $9(-212$ to 73$)$ & 0.879 \\
\hline \multicolumn{6}{|c|}{ Primary care patients swabbed $<5$ days after symptom onset } \\
\hline Unvaccinated & $334 / 182$ & Reference & - & Reference & - \\
\hline Vaccinated & $41 / 24$ & $7(-59$ to 45$)$ & 0.793 & $29(-38$ to 63$)$ & 0.319 \\
\hline \multicolumn{6}{|c|}{ Patients aged $<65$ years } \\
\hline Unvaccinated & $337 / 258$ & Reference & - & Reference & - \\
\hline Vaccinated & $20 / 35$ & $56(22$ to 75$)$ & 0.005 & $44(-11$ to 72$)$ & 0.095 \\
\hline \multicolumn{6}{|c|}{ Patients aged $\geq 65$ years } \\
\hline Unvaccinated & $24 / 23$ & Reference & - & Reference & - \\
\hline Vaccinated & $30 / 30$ & $4(-106$ to 55$)$ & 0.913 & $19(-146$ to 73$)$ & 0.710 \\
\hline
\end{tabular}

$\mathrm{Cl}$ : confidence interval.

a Vaccine effectiveness adjusted for sex, age ( $\langle 5 ; 5-14 ; 15-44 ; 45-64 ; \geq 65$ years), major chronic conditions, outpatient visits in the previous year, hospitalisation in the previous year, healthcare setting, and period of diagnosis.

There was one case of influenza $A\left(\mathrm{H}_{1} \mathrm{~N}_{1}\right)$ pdmog, not shown in this table.

Target population for vaccination includes people $\geq 60$ years-old and people with major chronic conditions. 


\section{TABLE 3}

Influenza vaccine effectiveness in preventing laboratory-confirmed influenza by vaccination status and time after vaccination, comparison of influenza-positive cases $(n=411)$ and test-negative controls $(n=346)$, Navarre,

12 Dec 2011-20 May 2012

\begin{tabular}{|c|c|c|c|c|c|}
\hline & Cases/controls & $\begin{array}{l}\text { Crude vaccine } \\
\text { effectiveness } \\
\%(95 \% \mathrm{Cl})\end{array}$ & $\mathrm{p}$ value & $\begin{array}{c}\text { Adjusted vaccine } \\
\text { effectiveness } \\
\%(95 \% \mathrm{Cl})^{\mathrm{a}}\end{array}$ & $\mathrm{p}$ value \\
\hline \multicolumn{6}{|l|}{ All swabbed patients } \\
\hline Unvaccinated & $361 / 281$ & Reference & - & Reference & - \\
\hline <100 days after vaccination & $11 / 24$ & $64(26$ to 83$)$ & 0.006 & $61(5$ to 84$)$ & 0.039 \\
\hline 100-119 days after vaccination & $15 / 16$ & $27(-50$ to 64$)$ & 0.392 & $42(-39$ to 75$)$ & 0.222 \\
\hline$\geq 120$ days after vaccination & $24 / 25$ & $25(-34$ to 58$)$ & 0.326 & $-35(-211$ to 41$)$ & 0.476 \\
\hline \multicolumn{6}{|l|}{ Influenza $\mathrm{A}\left(\mathrm{H}_{3}\right)$ cases } \\
\hline Unvaccinated & $335 / 281$ & Reference & - & Reference & - \\
\hline <100 days after vaccination & $11 / 24$ & $62(20$ to 81$)$ & 0.010 & $61(4$ to 84$)$ & 0.040 \\
\hline 100-119 days after vaccination & $15 / 16$ & $21(-62$ to 62$)$ & 0.514 & $39(-48$ to 74$)$ & 0.275 \\
\hline$\geq 120$ days after vaccination & $21 / 25$ & $29(-29$ to 61$)$ & 0.255 & $-55(-283$ to 37$)$ & 0.342 \\
\hline \multicolumn{6}{|l|}{ Target population for vaccination ${ }^{b}$} \\
\hline Unvaccinated & $112 / 98$ & Reference & - & Reference & - \\
\hline <100 days after vaccination & $7 / 21$ & 71 (28 to 88$)$ & 0.007 & $69(6$ to 90$)$ & 0.038 \\
\hline 100-119 days after vaccination & $15 / 14$ & $6(-104$ to 57$)$ & 0.871 & $39(-49$ to 75$)$ & 0.277 \\
\hline$\geq 120$ days after vaccination & $21 / 19$ & $3(-90$ to 51$)$ & 0.923 & $-51(-298$ to 42$)$ & 0.397 \\
\hline \multicolumn{6}{|l|}{ Primary healthcare patients } \\
\hline Unvaccinated & $337 / 185$ & Reference & - & Reference & - \\
\hline <100 days after vaccination & $10 / 13$ & $58(2$ to 82$)$ & 0.045 & 63 (2 to 96$)$ & 0.045 \\
\hline 100-119 days after vaccination & $14 / 5$ & $-54(-333$ to 45$)$ & 0.417 & $-2(-215$ to 67$)$ & 0.971 \\
\hline$\geq 120$ days after vaccination & $17 / 7$ & $-33(-227$ to 46$)$ & 0.530 & $-2(-194$ to 65$)$ & 0.971 \\
\hline \multicolumn{6}{|l|}{ Hospitalised patients } \\
\hline Unvaccinated & $21 / 85$ & Reference & - & Reference & - \\
\hline <100 days after vaccination & $1 / 10$ & $59(-234$ to 95$)$ & 0.401 & $65(-277$ to 97$)$ & 0.383 \\
\hline 100-119 days after vaccination & $1 / 9$ & $55(-275$ to 95$)$ & 0.460 & $78(-126$ to 98$)$ & 0.202 \\
\hline$\geq 120$ days after vaccination & $7 / 15$ & $-89(-522$ to 32$)$ & 0.220 & $-182(-1,219$ to 40$)$ & 0.187 \\
\hline \multicolumn{6}{|c|}{ Primary care patients swabbed $<5$ days after symptom onset } \\
\hline Unvaccinated & $334 / 182$ & Reference & - & Reference & - \\
\hline$\langle 100$ days after vaccination & $10 / 12$ & $55(-7$ to 81$)$ & 0.072 & $58(-12$ to 84$)$ & 0.084 \\
\hline 100-119 days after vaccination & $14 / 5$ & $-53(-330$ to 46$)$ & 0.425 & o (-211 to 68$)$ & 0.999 \\
\hline$\geq 120$ days after vaccination & $17 / 7$ & $-32(-225$ to 46$)$ & 0.541 & o $(-189$ to 66$)$ & 0.991 \\
\hline \multicolumn{6}{|c|}{ Week 50/2011 to 8/2012 (12 Dec 2011-26 Feb 2012) } \\
\hline Unvaccinated & $298 / 195$ & Reference & - & Reference & - \\
\hline <100 days after vaccination & $10 / 24$ & $73(42$ to 87$)$ & 0.001 & $65(11$ to 86$)$ & 0.027 \\
\hline 100-119 days after vaccination & $13 / 16$ & $47(-13$ to 75$)$ & 0.101 & $48(-32$ to 79$)$ & 0.168 \\
\hline$\geq 120$ days after vaccination & $11 / 2$ & $-260(-1,541$ to 21$)$ & 0.098 & $-375(-2,513$ to 14$)$ & 0.073 \\
\hline \multicolumn{6}{|l|}{ Patients aged $<65$ years } \\
\hline Unvaccinated & $337 / 258$ & Reference & & Reference & \\
\hline <100 days after vaccination & $6 / 13$ & $65(6$ to 87$)$ & 0.038 & $47(-63$ to 83$)$ & 0.269 \\
\hline $100-119$ days after vaccination & $6 / 7$ & $34(-98$ to 78$)$ & 0.454 & $54(-55$ to 86$)$ & 0.210 \\
\hline$\geq 120$ days after vaccination & $8 / 15$ & $59(2$ to 83$)$ & 0.044 & $32(-111$ to 78$)$ & 0.503 \\
\hline \multicolumn{6}{|l|}{ Patients aged $\geq 65$ years } \\
\hline Unvaccinated & $24 / 23$ & Reference & & Reference & \\
\hline <100 days after vaccination & $5 / 11$ & $56(-145$ to 87$)$ & 0.176 & $85(-8$ to 98$)$ & 0.059 \\
\hline 100-119 days after vaccination & $9 / 9$ & $4(-184$ to 68$)$ & 0.939 & $24(-224$ to 82$)$ & 0.715 \\
\hline$\geq 120$ days after vaccination & $16 / 10$ & $-53(-307$ to 42$)$ & 0.390 & $-208(-1,563$ to 43$)$ & 0.192 \\
\hline
\end{tabular}

$\mathrm{Cl}$ : confidence interval.

a Vaccine effectiveness adjusted for sex, age $(\langle 5 ; 5-14 ; 15-44 ; 45-64 ; \geq 65$ years), major chronic conditions, outpatient visits in the previous year, hospitalisation in the previous year, healthcare setting, and period of diagnosis.

${ }^{b}$ Target population for vaccination includes people $\geq 60$ years-old and people with major chronic conditions. 
The point estimates of the influenza VE ranged between $61 \%$ and $69 \%$ during the first 100 days after vaccination in the analyses restricted to cases of influenza $A\left(H_{3}\right)$, to persons with an indication for influenza vaccination, to primary care patients, and to hospitalised patients, although this last result was not statistically significant. However, in all these analyses the vaccine had practically zero effectiveness at 120 or more days after vaccination (Table 3 ). In persons under 65 years of age the VE declined little with time since vaccination, whereas in those aged 65 years or older the OR for the risk of influenza was 20.81 (95\% Cl: 2.14 to 202.71; $p=0.009$ ) for those vaccinated more than 120 days previously versus those vaccinated less than 100 days previously.

\section{Genetic characterisation}

In total 102 isolates obtained from the confirmed cases, were further characterised by phylogenetic analysis of the HA1 sequence of the haemagglutinin gene in the National Influenza Centre - Madrid laboratory: 90 were influenza $A\left(\mathrm{H}_{3} \mathrm{~N}_{2}\right), 11$ influenza $B$ and one was influenza $A\left(\mathrm{H}_{1} \mathrm{~N}_{1}\right)$ pdmog. The strains most frequently identified were similar to $A /$ Victoria/361/2011 $\left(\mathrm{H}_{3} \mathrm{~N}_{2}\right)$ (41.2\%), A/England/259/2011( $\left.\mathrm{H}_{3} \mathrm{~N}_{2}\right) \quad$ (24.5\%), $\mathrm{A} /$ lowa/19/2010(H3N2) (20.6\%) and B/ Bangladesh/3333/2007(Yamagata) (9.8\%). The proportions of strains were similar in the two periods from week 50/2011 to 8/2012 (12 December 2011 to 26 February 2012) and from week $9 / 2012$ to $20 / 2012$ (27 February to 20 May 2012), except for a reduced proportion of characterisations of strain A/England/259/2011( $\left.\mathrm{H}_{3} \mathrm{~N}_{2}\right)$ and an increase of B/Bangladesh/3333/2007(Yamagata) (Table 4).

\section{Discussion}

The results of this study suggest that on average, the seasonal influenza vaccine had a low protective effect in preventing laboratory-confirmed influenza during the 2011/12 season in Navarre. Most of the strains we characterised showed reduced reactivity with postinfection ferret antiserum raised against the vaccine viruses, suggesting a certain degree of vaccine-virus mismatch [19]. Although the confidence intervals were wide, similar estimates were obtained in analyses restricted to the target population for vaccination, to primary healthcare patients, or to patients swabbed within the first four days after symptom onset, which strengthens the conclusion and rules out possible biases. Evaluation of VE in preventing cases of influenza $A\left(\mathrm{H}_{3}\right)$ only, also yielded similar estimates.

The early estimates of influenza VE for the first part of the season were higher than what we found for the complete season $[20,21]$, which suggests a decline in VE over time. Two possible mechanisms, or a combination of both, could explain this reduced VE. The first is a change in the viruses circulating during the season, either due to appearance of another virus type or due to antigenic drift of circulating viruses, resulting in a loss of the match with the vaccine viruses. Our results do not support this mechanism, since the only relevant change in the circulating viruses was an increase in influenza B viruses, and low VE was also observed when we evaluated the effectiveness of the vaccine against influenza $\mathrm{A}\left(\mathrm{H}_{3}\right)$ only.

The second possible mechanism is waning immunity in those who received the vaccine. It has been reported that antibody levels begin to fall one month after

\section{TABLE 4}

Distribution of influenza cases by type of virus and distribution of cases with characterisation by strains in two calendar periods. Navarre, Spain, 2011-2012

\begin{tabular}{|c|c|c|c|}
\hline & $\begin{array}{c}\text { Week 50/2011 to 8/2012 (12 Dec } \\
\text { 2011-26 Feb 2012) } \\
\text { n (\%) }\end{array}$ & $\begin{array}{c}\text { Week 9/2012 to 20/2012 (27 Feb } \\
-20 \text { May 2012) } \\
\text { n (\%) }\end{array}$ & $\mathrm{p}$ value \\
\hline \multicolumn{4}{|l|}{ All cases } \\
\hline Influenza $\mathrm{A}\left(\mathrm{H}_{3}\right)$ & $325(97.9)$ & $57(72.2)$ & $<0.001$ \\
\hline Influenza A(H1N1)pdmo9 & $1(0.3)$ & o (o) & 1.000 \\
\hline Influenza B & $6(1.8)$ & $22(17.8)$ & $<0.001$ \\
\hline Total & $332(100)$ & 79 (100) & - \\
\hline \multicolumn{4}{|l|}{ Cases with characterisation } \\
\hline Influenza A/Victoria/361/2011( $\left.\mathrm{H}_{3} \mathrm{~N}_{2}\right)$ & $34(42.5)$ & $8(36.4)$ & 0.635 \\
\hline Influenza A/England/259/2011( $\left.\mathrm{H}_{3} \mathrm{~N}_{2}\right)$ & $24(30.0)$ & $1(4 \cdot 5)$ & 0.012 \\
\hline Influenza A/Stockholm/18/2011( $\left.\mathrm{H}_{3} \mathrm{~N}_{2}\right)$ & $2(2.5)$ & $\mathrm{o}(0)$ & 1.000 \\
\hline Influenza A/lowa/19/2010( $\left.\mathrm{H}_{3} \mathrm{~N}_{2}\right)$ & $17(21.3)$ & $4(18.2)$ & 1.000 \\
\hline Influenza B/Bangladesh/3333/2007(Yamagata) & $2(2.5)$ & $8(36.4)$ & $<0.001$ \\
\hline Influenza B/Brisbane/6o/2008(Victoria) & $\mathrm{o}(0)$ & $1(4.5)$ & 0.216 \\
\hline $\begin{array}{l}\text { Influenza A/St Petersburg/100/2011(H1N1) } \\
\text { pdmo9 }\end{array}$ & $1(1.3)$ & o (o) & 1.000 \\
\hline Total & $80(100)$ & $22(100)$ & - \\
\hline
\end{tabular}


administration of the influenza vaccine [10]. This loss of immune response is more pronounced in older persons [10-12]. The results of our study show a decline in the VE beginning 100 days after vaccination, primarily in persons aged 65 years or older. This finding could be explained by an immunosenescence phenomenon, aggravated by the long time between vaccination and virus circulation, which was longer than in most other seasons [13], and the limited match between vaccine and circulating strains $[20,21]$.

Longer time between symptom onset and swabbing has been associated with reduced sensitivity in virus detection, which could underestimate VE [6]. We controlled for this effect mainly in the design of our study, since $99 \%$ of the swabs from primary healthcare patients were taken within the first four days after symptom onset. Moreover, we repeated the analysis after eliminating the cases swabbed after the first four days, and no relevant changes in the estimate of VE were found.

The present study included both outpatient and hospital cases systematically recruited in a previously defined population. Primary care patients made up the bulk of subjects in our study and, when the analysis was limited to these patients, the VE was maintained. The number of cases treated in hospitals was small, which did not allow us to obtain a specific estimate of the VE in preventing hospitalised cases.

Although institutionalised patients were not included in this study, several influenza outbreaks in nursing homes with high vaccination coverage were detected in Navarre in the 2011/12 season [22]. This may be considered another consequence of the low VE.

This case-control analysis included only laboratoryconfirmed cases and compared them with test-negative controls recruited in the same healthcare settings before either patient or physician knew the laboratory result, a fact that provides better comparability and reduces selection bias [6]. This type of design has been used in other studies that have evaluated influenza VE $[20,21,23,24]$. The case-control study was nested in a population cohort for which extensive and reliable databases were available, and which was treated in hospitals and primary healthcare by physicians trained to detect and swab ILI patients, all of which can prevent unmeasured confounding [25].

In interpreting the results, some limitations must be kept in mind. The study size was insufficient to demonstrate a VE under $40 \%$, which was reflected in wide confidence intervals that included zero. It may not be possible to generalise the results and apply them to other geographical areas, although other published studies in the same influenza season are consistent with our data $[20,21]$. Although RT-PCR has high sensitivity for the detection of influenza virus, we cannot completely rule out some false negative results, which would cause a small underestimation of the VE. Although all the analyses were adjusted for the commonly recognised confounding factors, some residual confusion is possible [6].

These results suggest that VE may vary throughout the influenza season. The early estimates of influenza VE obtained in mid-season may drop during the season. This situation should be kept in mind given its implications for clinical practice and public health; it should not be interpreted as an error in the estimates, but as a description of reality. These early estimates remain enormously useful in redirecting preventive strategies during the influenza season and because they can aid the selection of strains to be included in the following season's vaccine $[20,21]$.

The description of situations in which influenza VE is low should serve as a stimulus to design better influenza vaccines [26], to improve the selection of strains contained in the vaccine, to choose the most appropriate time for vaccination in each area, to encourage vaccination of caregivers of high-risk individuals, and to highlight the importance of other preventive measures that complement vaccination in high-risk populations, such as promotion of basic hygiene measures and avoidance of contact with influenza cases [27]. Early treatment with antiviral drugs should be considered in persons diagnosed with influenza who have a high risk of complications, regardless of vaccination status [28]. In seasons when influenza starts late, it may be useful to revaccinate persons with a high risk of complications, especially those who may have a reduced immune response due to immunosenescence or immunodepression.

Even in seasons in which the effectiveness of influenza vaccine is low, it may appreciably reduce the number of cases and hospitalisations in high-risk persons. In the 2011/12 season in Navarre, the vaccine managed to avoid almost one third of the influenza cases in the vaccinated at-risk population; while not entirely satisfactory, this result is important in terms of individual and public health.

\section{Conclusions}

Our results support a low protective effect of the 2011/12 seasonal vaccine in Navarre and suggest a decline in VE in the elderly with time since vaccination. Even under these conditions, annual immunisation of high-risk populations against influenza remains of interest, although it should be complemented with other preventive initiatives such as basic hygiene measures, vaccination of caregivers and avoidance of contact with influenza cases.

\section{Acknowledgements}

This work was supported by the I-MOVE (Influenza Monitoring Vaccine Effectiveness in Europe) programme funded by the European Centre for Disease Prevention and Control 
(ECDC), by the Carlos III Institute of Health (GRog/0028 and PSog/01179), and by the Spanish Ministry of Health (EC11-302).

The members of the Primary Health Care Sentinel Network of Navarre are: I Abad, P Aldaz, E Álvarez, JJ Arana, I Arceiz, E Arina, MD Artajo, A Arza, B Azagra, FC Bartolome, C Bernués, J Berraondo, C Bolea, A Brugos, S Buil, B Cano, MV Castresana, JC Cenoz, F Cia, B Compains, F Cortés, B Churío, EM Da Costa, J Díez Espino, M Doiz, FJ Escribano, MJ Esparza, V Etayo, L Fanlo, C Fernández Alfaro, B Flamarique, J Gamboa, E Gembero, AB German, A Giner, M Gómara, N Goñi, MJ Guillorme, JO Guiu, JC Gurbindo, MJ Guruchaga, JA Heras, MC Hijos, MS Indurain, B Iñigo, SE Juan Belloc, J Jurio, $O$ Lecea, MP León, JJ Longás, MT Maquirriain, J Miner, E Montoya, M Moreno, U Navarro, O Olmedo, FJ Orozco, M Orte, J Palau, F Pérez Afonso, C Pérez Lecumberri, P Pérez Pascual, A Prado Virto, M Prado Santamaria, A Puig Arrastia, E Ridruejo, M Ramos, BE Rípodas, M Rodríguez, MA Roncal, I Ruiz Puertas, C Sánchez Vázquez, MA Senosiain, J Sola, M Sota, P Uhalte, ME Ursua, IA Urtasun, MJ Vigata, MT Virto, JM Vizcay.

The members of the Network for Influenza Surveillance in Hospitals of Navarre are: P Artajo, E Bernaola, J Chamorro, P Fanlo, F Gil, M Gabari, J Hueto, E Maraví, C Pérez, M Ruiz (Complejo Hospitalario de Navarra), J Núñez (Clínica Universidad de Navarra), A Navascués, M Ortega, M Torres (Hospital Reina Sofía, Tudela), F Lameiro, A Petit (Hospital García Orcoyen, Estella).

\section{References}

1. Glezen WP. Serious morbidity and mortality associated with influenza epidemics. Epidemiol Rev. 1982;4:25-44.

2. Thompson WW, Shay DK, Weintraub E, Brammer L, Bridges CB, Cox NJ, et al. Influenza-associated hospitalizations in the United States. JAMA. 2004;292(11):1333-40.

3. Nichol KL, Nordin JD, Nelson DB, Mullooly JP, Hak E. Effectiveness of influenza vaccine in the community-dwelling elderly. N Engl J Med. 2007;357(14):1373-81

4. Osterholm MT, Kelley NS, Sommer A, Belongia EA. Efficacy and effectiveness of influenza vaccines: a systematic review and meta-analysis. Lancet Infect Dis. 2012;12(1):36-44.

5. Orenstein WA, Bernier RH, Hinman AR. Assessing vaccine efficacy in the field. Further observations. Epidemiol Rev. 1988;10:212-241.

6. Valenciano M, Kissling E, Ciancio BC, Moren A. Study designs for timely estimation of influenza vaccine effectiveness using European sentinel practitioners networks. Vaccine. 2010;28(46):7381-8.

7. Jackson LA, Jackson ML, Nelson JC, Neuzil KM, Weiss NS. Evidence of bias in estimates of influenza vaccine effectiveness in seniors. Int J Epidemiol. 2006;35(2):337-44.

8. Jefferson T, Rivetti A, Rudin M, Pietrantonj, Demicheli V. Efficacy and effectiveness of influenza vaccines in elderly people: a systematic review. Lancet. 2005;366(9492):1165-74.

9. Orenstein EW, De Serres G, Haber MJ, Shay DK, Bridges CB, Gargiullo P, et al. Methodologic issues regarding the use of three observational study designs to assess influenza vaccine effectiveness. Int J Epidemiol. 2007;36(3):623-631.

10. Song JY, Cheong HJ, Hwang IS, Choi WS, Jo YM, Park DW, et al. Long-term immunogenicity of influenza vaccine among the elderly: Risk factors for poor immune response and persistence. Vaccine. 2010;28(23):3929-35.

11. Reber AJ, Chirkova T, Kim JH, Cao W, Biber R, Shay DK, et al. Immunosenescence and challenges of vaccination against influenza in the aging population. Aging Dis. 2012;3(1):68-90.

12. Targonski PV, Jacobson RM, Poland GA. Immunosenescence: role and measurement in influenza vaccine response among the elderly. Vaccine. 2007; 25(16):3066-9.

13. Sistema de vigilancia de la gripe en España. [Influenza surveillance system in Spain]. Vigilancia de la gripe en España - Temporada 2011-12 [Influenza surveillance in Spain - 2011/12 season]. Madrid: Instituto de Salud Carlos III. [Accessed: 30 Jan 2013]. Spanish. Available from: http://vgripe.isciii. es/gripe/documentos/20112012/InformesAnuales/Informe GRIPE Temporada 2011-12 v.3septiembre2012.pdf
14. Instituto de Salud Pública de Navarra. [Public Health Institute of Navarre]. Protocolo de vacunación antigripalantineumocócica 2011-2012 [Influenza-pneumococcal vaccination protocol 2011/12]. Boletín Informativo. 2010;63:25. Spanish. Available from: http://www.navarra.es/NR/ rdonlyres/AECCD760-AB2A-4841-818A-FA53478FD6DC/199452/ BOL63GRIPE.pdf

15. Recommended composition of influenza virus vaccines for use in the 2011-2012 northern hemisphere influenza season. Wkly Epidemiol Rec. 2011;86(10):86-90.

16. European Commission. Commission Decision of 28 April 2008 amending Decision 2002/253/EC laying down case definitions for reporting communicable diseases to the Community network under Decision No 2119/98/EC of the European Parliament and of the Council. Luxembourg: Official Journal of the European Union. 18.6.2008:L 159/46. Available from: http://eur-lex.europa.eu/LexUriServ/LexUriServ.do?uri=0J:L:2 008:159:0046:0090:EN:PDF

17. Aguilar I, Reyes M, Martínez-Baz I, Guevara M, Albeniz E, Belza MJ, et al. Use of the vaccination register to evaluate influenza vaccine coverage in seniors in the 2010/11 influenza season, Navarre, Spain. Euro Surveill. 2012;17(17): pii=20154. Available from: http://www.eurosurveillance.org/ViewArticle. aspx?Articleld $=20154$

18. Fuertes Goñi MC, Elizalde L, De Andrés MR, García Castellano P, Urmeneta S, Uribe JM, et al. Atención al paciente inmigrante: realidad y percepción de los profesionales de 6 zonas de Atención Primaria de Navarra [Care for immigrant patients: facts and professionals' perception in 6 primary healthcare zones in Navarre]. An Sist Sanit Navar. 2010;33(2):179-90. Spanish.

19. Community Network of Reference Laboratories for Human Influenza in Europe (CNRL). Influenza virus characterization. Summary Europe, June 2012. Technical document. Stockholm: European Centre for Disease Prevention and Control (ECDC); 2012. Available from: http://www.ecdc.europa.eu/en/ publications/Publications/Influenza-visus-characterisationJune-2012.pdf

20. Jiménez-Jorge S, de Mateo S, Pozo F, Casas I, Garcia Cenoz M, Castilla J, et al. Early estimates of the effectiveness of the $2011 / 12$ influenza vaccine in the population targeted for vaccination in Spain, 25 December 2011 to 19 February 2012. Euro Surveill. 2012;17(12). pii: 20129. Available from: http:// www.eurosurveillance.org/ViewArticle.aspx?Articleld=20129

21. Kissling E, Valenciano M, I-MOVE Case-Control Studies Team. Early estimates of seasonal influenza vaccine effectiveness in Europe among target groups for vaccination: results from the I-MOVE multicentre case-control study, 2011/12. Euro Surveill. 2012;17(15). pii: 20146. Available from: http://www. eurosurveillance.org/ViewArticle.aspx?Articleld=20146

22. Castilla J, Cía F, Zubicoa J, Reina G, Martínez-Artola V, Ezpeleta C. Influenza outbreaks in nursing homes with high vaccination coverage in Navarre, Spain, 2011/12. Euro Surveill. 2012;17(14):pii=20141. Available from: http://www. eurosurveillance.org/ViewArticle.aspx?Articleld=20141

23. Kissling E, Valenciano M, Cohen JM, Oroszi B, Barret AS, Rizzo C, et al. I-MOVE multi-centre case control study 201011: Overall and stratified estimates of influenza vaccine effectiveness in Europe. PLoS One. 2011;6(11):e27622.

24. Pebody R, Hardelid P, Fleming D, McMenamin J, Andrews N, Robertson C, et al. Effectiveness of seasonal 2010/11 and pandemic influenza $A\left(\mathrm{H}_{1} \mathrm{~N}_{1}\right) 2009$ vaccines in preventing influenza infection in the United Kingdom: mid-season analysis 2010/11. Euro Surveill. 2011;16(6): $\mathrm{pii}=19791$. Available from: http://www.eurosurveillance.org/ViewArticle. aspx?Articleld $=19791$

25. Groenwold RH, Hoes AW, Nichol KL, Hak E. Quantifying the potential role of unmeasured confounders: the example of influenza vaccination. Int J Epidemiol. 2008;37(6):1422-9.

26. Lambert LC, Fauci AS. Influenza vaccines for the future. $\mathrm{N}$ Engl J Med. 2010;363(21):2036-44.

27. Godoy P, Castilla J, Delgado-Rodríguez M, Martín V, Soldevila $\mathrm{N}$, Alonso J, et al. Effectiveness of hand hygiene and provision of information in preventing influenza cases requiring hospitalization. Prev Med. 2012;54(6):434-9.

28. Fiore AE, Fry A, Shay D, Gubareva L, Bresee JS, Uyeki TM, et al. Antiviral agents for the treatment and chemoprophylaxis of influenza - Recommendations of the Advisory Committee on Immunization Practices (ACIP). MMWR Recomm Rep. 2011;60(1):1-24. 